\title{
Influence of Sedimentation of Atoms on Structural and Thermoelectric Properties of Bi-Sb Alloys
}

\author{
KAMILA JANUSZKO,${ }^{1,2,4}$ ARTUR STABRAWA, ${ }^{1}$ YUDAI OGATA, ${ }^{3}$ \\ MAKOTO TOKUDA, ${ }^{2}$ JAHIRUR ISLAM KHANDAKER, ${ }^{2}$ \\ KRZYSZTOF WOJCIECHOWSKI ${ }^{1}$ and TSUTOMU MASHIMO ${ }^{2}$
}

1.-Thermoelectric Research Laboratory, Faculty of Materials Science and Ceramics, AGH University of Science and Technology, 30-059 Cracow, Poland. 2.-Institute of Pulsed Power, Kumamoto University, 2-39-1 Kurokami, 860-8555 Kumamoto, Japan. 3.-Research Group for Spin-energy transfer Materials, Advanced Science Research Center, Japan Atomic Energy Agency, Tokai, Ibaraki 319-1195, Japan. 4.—e-mail: kamila.januszko@gmail.com

Functionally graded thermoelectric materials (FGTMs) have been prepared by sedimentation of atoms under a strong gravitational field. Starting samples of $\mathrm{Bi}_{x} \mathrm{Sb}_{1-x}$ alloys with different composition $x$ were synthesized by melting of metals and subsequent annealing of quenched samples. The thermoelectric properties (Seebeck coefficient, electrical conductivity) of the starting materials were characterized over the temperature range from $300 \mathrm{~K}$ to $525 \mathrm{~K}$. Strong gravity experiments were performed in a unique ultracentrifuge apparatus under acceleration of over $0.5 \times 10^{6} \mathrm{G}$ at temperatures of $538 \mathrm{~K}$ and $623 \mathrm{~K}$. Changes of the microstructure and chemical composition were analyzed using scanning electron microscopy with energy-dispersive x-ray spectroscopy analysis. The distribution of the Seebeck coefficient of the Bi-Sb alloys was characterized by scanning thermoelectric microprobe. As a result of sedimentation, large changes in chemical composition $(x=0.45$ to 1$)$ were obtained. It was found that the changes in chemical composition were correlated with alterations of the Seebeck coefficient. The obtained experimental data allowed the development of a semiempirical model for the selection of optimal processing parameters for preparation of $\mathrm{Bi}-\mathrm{Sb}$ alloys with required thermoelectric properties.

Key words: Functionally graded thermoelectric materials, strong gravitational field, sedimentation of atoms, Bi-Sb alloys

\section{INTRODUCTION}

Thermoelectric materials are currently being considered for construction of innovative devices for waste heat recovery and cooling purposes. Their advantages include reliability and no need for maintenance, but there is still a need for research on efficiency improvement of such materials. For characterization of the usefulness of materials in terms of energy conversion, the thermoelectric figure-of-merit parameter $Z T=\alpha^{2} \sigma T / \lambda$ (where $\alpha$ is the Seebeck coefficient, $\sigma$ is the electrical conductivity,

(Received June 5, 2015; accepted December 14, 2015;

published online February 1, 2016) and $\lambda$ is the thermal conductivity) is commonly applied. The $Z T$ value of numerous thermoelectric element (TE) materials (e.g., $\mathrm{PbTe}, \mathrm{Bi}_{2} \mathrm{Te}_{3}, \mathrm{CoSb}_{3}$ ) usually peaks in a relatively narrow temperature range $\Delta T$ of about $50 \mathrm{~K}$ to $100 \mathrm{~K}$. Therefore the average efficiency of thermoelectric elements in which a wider temperature difference exists is significantly reduced due to the fact that, in some regions, the $Z T$ parameter is lower than the maximum value. One of the typical approaches used to overcome this problem is preparation of inhomogeneous elements by joining of a few segments made of different alloys (e.g., $\mathrm{Bi}_{2} \mathrm{Te}_{3}, \mathrm{CoSb}_{3}$ ) with thermoelectric properties carefully selected for the temperatures present in the TE element. Such segmented 
thermoelectric legs made from materials having complementary properties over the whole temperature range offer significantly better efficiency compared with uniform elements made from a single material. $^{1-4}$

Theoretical studies on segmented $\operatorname{legs} s^{5,6}$ state that it is possible to increase the absolute efficiency from about $5 \%$ in commercially available materials to $18 \%$. Various compounds are considered as materials for construction of segmented legs, with $\mathrm{Bi}_{2} \mathrm{Te}_{3},{ }^{5,7,8}$ skutterudites (e.g., $\mathrm{CoSb}_{3}$-based materials), ${ }^{8,9}$ lead tellurides, ${ }^{10,11}$ silicon-germanium alloys, ${ }^{12,13}$ zinc antimonides, ${ }^{14,15}$ and Te/Sb/Ge/Ag (TAGS) materials such as $(\mathrm{AgSbTe})_{0.15}(\mathrm{GeTe})_{0.85},{ }^{16,17}$ being only some of the most commonly investigated.

Nonetheless, such use of various materials requires numerous problems to be addressed, including the increased resistance of junctions and inconsistency of mechanical and electrical properties in the interface regions, potentially limiting one of the greatest advantages of thermoelectric devices, namely their long lifespan.

Numerous approaches to the development of inhomogeneous materials have been introduced since Ioffe ${ }^{18}$ originally revealed that achieving an appropriate gradient in the carrier concentration could significantly enhance the performance of a thermoelectric leg made of a single thermoelectric material; For example, it has been shown theoretically that preparation of $\mathrm{Bi}_{2} \mathrm{Te}_{3}-\mathrm{Sb}_{2} \mathrm{Te}_{3}$ with optimal inhomogeneity allows an increase in the maximum energy conversion efficiency by as much as $50 \%{ }^{19}$ Similar results have been obtained for various materials developed for both power and cooling applications. ${ }^{20-23}$

One of the methods for preparation of graded materials ${ }^{24,25}$ is deposition of a dopant in the form of a layer on the surface of the thermoelectric material with subsequent annealing of the sample. However, this method has limitations in terms of control of the depth of dopant penetration as well as the miscibility of the dopant under the conditions applied in the experiment.

More advanced methods for preparation of inhomogeneous thermoelectric materials originate from the Czochralski and Bridgman techniques for single-crystal growth, ${ }^{26,27}$ which allow single-crystalline materials to be obtained in a natural way with a fine profile of dopant concentration even along the whole sample length. These methods appear to be relatively simple, but their practical application is limited because of difficulties in preparation of materials with required dopant concentrations that are far from the local equilibrium achieved during the crystallization process.

Our research is focused on development of a new method for preparation of functionally graded thermoelectric materials with controlled profiles of transport properties that avoids the aforementioned limitations. To achieve this aim, a special ultracentrifuge allowing creation of a strong acceleration field of over $10^{6} \mathrm{G}$ at elevated temperatures of up to $700 \mathrm{~K}$ was applied.

The usefulness of this technique ${ }^{28}$ for controlled sedimentation of atoms in solid state (Fig. 1) was confirmed by Mashimo in regard to various semiconductors and metals. ${ }^{29-31}$ Preliminary results reported by Mashimo for Bi-Sb alloys ${ }^{31,32}$ showed that sedimentation of $\mathrm{Bi}-\mathrm{Sb}$ alloys at acceleration $a=1 \times 10^{6} \mathrm{G}$ and temperature above $490 \mathrm{~K}$ allows preparation of samples with a very wide range of chemical composition.

The Bi-Sb alloys that are the subject of this study are well-known thermoelectric materials with very good thermoelectric properties at low temperatures, leading to their consideration for cooling purposes. The advantages of this system include its simplicity (binary alloy), its simple phase diagram, as well as the thorough knowledge available on its chemical and physical properties. A specific feature of such Bi$\mathrm{Sb}$ alloys is the anisotropy of the physical properties occurring in single crystals as a result of their rhombohedral structure (in space group $R-3 / m$ ). ${ }^{33,34}$ The highest $Z T$ and Seebeck coefficient values are measured in the $c$-axis crystallographic direction. ${ }^{33}$ Such anisotropy can also often be observed even in polycrystalline samples with homogeneous chemical composition if their method of preparation leads to ordering of crystallites in a specific direction. ${ }^{35-37}$

The aim of this work is to develop and master a new method for obtaining FGTM materials. Therefore, we performed experiments under various conditions for a series of Bi-Sb samples with different chemical compositions. The gathered experimental data allowed us to determine the influence of the basic parameters of the sedimentation procedure (i.e., initial sample composition, temperature, acceleration, and time) on the chemical, microstructural, and thermoelectric properties of the resulting material. The collected experimental data thus form the basis for a semiempirical model allowing selection of optimal conditions for preparation of desired profiles of electronic properties.

\section{EXPERIMENTAL PROCEDURES}

Samples of the initial Bi-Sb alloys were prepared by mixing high-purity elements to obtain appropriate $\mathrm{Bi}: \mathrm{Sb}$ atomic ratios (6:4, 7:3, 8:2, 9:1). The ingots were closed in evacuated quartz ampoules and melted in a rocking furnace at $1000 \mathrm{~K}$ for $2 \mathrm{~h}$. Next, the samples were quenched and annealed for $336 \mathrm{~h}$ at $520 \mathrm{~K}$ to obtain uniform chemical composition.

The electrical conductivity of samples was measured by the four-probe alternating-current (AC) method, together with Seebeck coefficient measurement, over the temperature range from $300 \mathrm{~K}$ to $525 \mathrm{~K}$. The results of these measurements were used for calculation of the thermoelectric power factor $\alpha^{2} \sigma$ of the initial materials. Samples for sedimentation experiments were cut and polished into cuboid shape with approximate dimensions of 

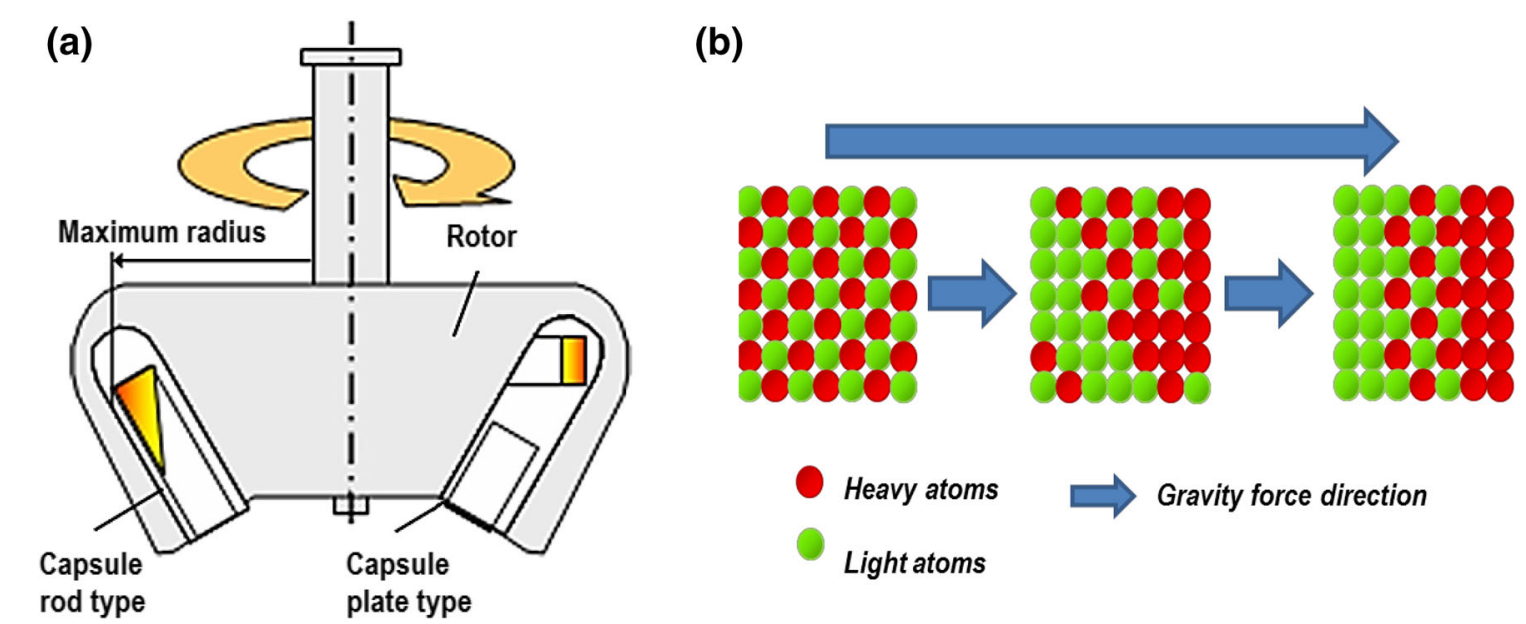

Heavy atoms

Gravity force direction

Light atoms

Fig. 1. (a) Schema of a rotor with capsules for sedimentation experiment. (b) Mechanism of sedimentation of atoms in the strong acceleration field.

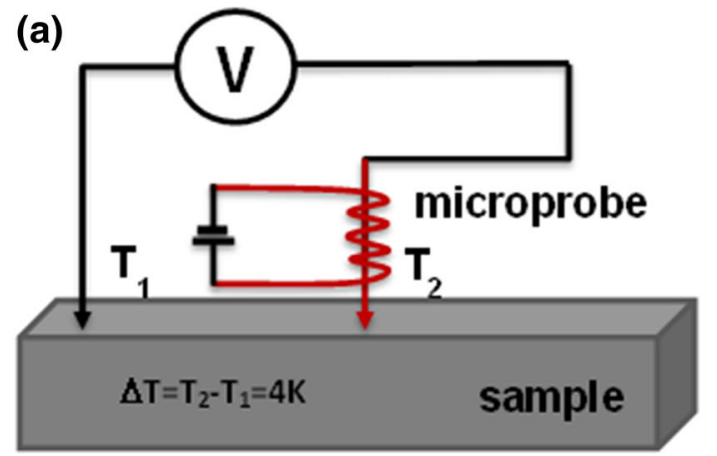

(b)

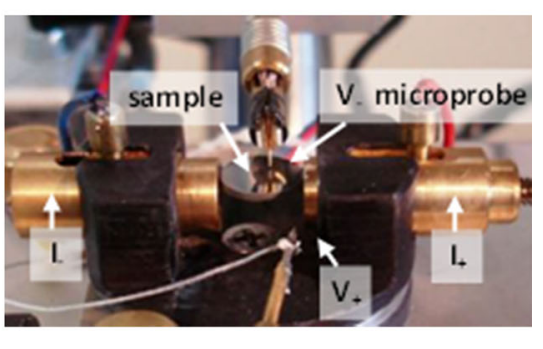

Fig. 2. (a) Schema of scanning thermoelectric microprobe. (b) Tip of the probe and the sample in a holder.

$2.5 \mathrm{~mm} \times 3.0 \mathrm{~mm} \times 3.5 \mathrm{~mm}$. The thermoelectric properties of the materials were characterized in the direction of crystallization.

Local Seebeck coefficient measurements by scanning thermoelectric microprobe (STM) were performed on three perpendicular surfaces of initial samples to examine the uniformity of the thermoelectric properties after annealing. During STM analysis, the sample was placed between two electrodes (Fig. 2b) and moved underneath the probe in the horizontal plane. The tip of the STM probe was kept at $4 \mathrm{~K}$ above the temperature of the sample. At each position, the probe was lowered onto the sample's surface, 30 data points were collected during about $2 \mathrm{~s}$, and statistical parameters were calculated.

The thermal conductivity and hardness of the material significantly affect the results of STM measurements. Elimination of the influence of these properties on the measured values of thermopower is a very important experimental issue. To overcome this problem, we decided to calibrate the apparatus using four reference samples (A, B, C, and D) with different chemical compositions ranging from $\mathrm{Bi}_{60} \mathrm{Sb}_{40}$ to $\mathrm{Bi}_{90} \mathrm{Sb}_{10}$. The average Seebeck coefficient of the reference samples had been determined using a classical apparatus for thermopower measurements. Figure 3 shows an example result for a graded sample.

For measurements of the global thermoelectric properties (i.e., Seebeck coefficient and electrical conductivity) of the reference samples, cylindrical samples of approximately $8 \mathrm{~mm}$ to $12 \mathrm{~mm}$ length and $3 \mathrm{~mm}$ diameter were prepared and placed in special holders coated with silver paste to ensure proper heat transfer. The electrical conductivity was measured by the four-probe AC method. The reference samples had holes $(0.6 \mathrm{~mm}$ diameter $)$ drilled near edges, in which voltage probes and thermocouples were inserted. Measurements of electrical properties were performed over the temperature range from $300 \mathrm{~K}$ to $525 \mathrm{~K}$. The microstructure and chemical composition were characterized by scanning microscope (NOVA NANO SEM 200 or JEOL JSM6460LV) equipped with x-ray spectroscopy (EDX).

Samples with uniform chemical composition and Seebeck coefficient distribution were put into the plate capsules as shown in Fig. 1 and graded in the ultracentrifuge (at Kumamoto University, Japan) under the conditions listed in Table I, selected according to the phase diagram of the Bi-Sb system. Samples were heated by a carbon heater placed in the ultracentrifuge 
(a)

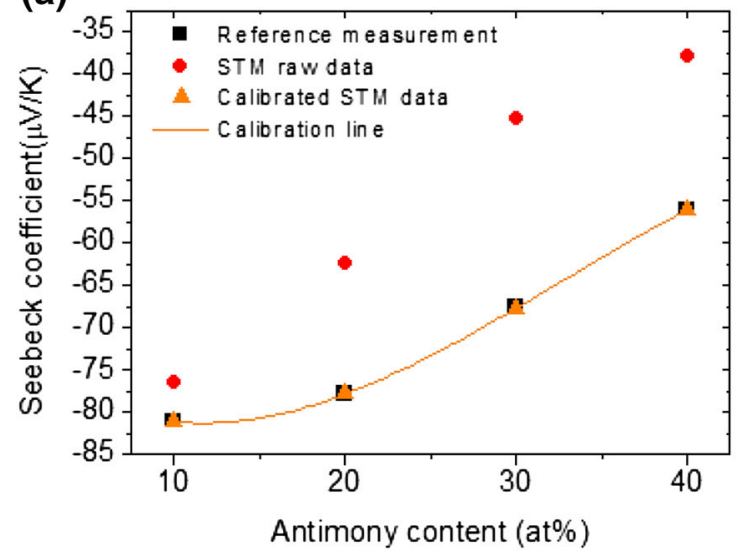

(b)

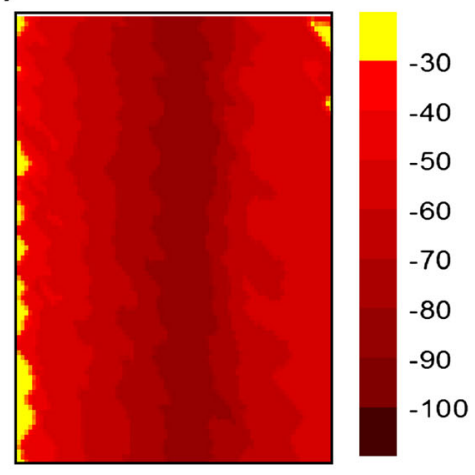

Fig. 3. (a) Calibration of Seebeck coefficient from STM measurement. (b) Seebeck coefficient map of $\mathrm{Bi}_{90} \mathrm{Sb}_{10}$ sample after gradation and calibration; spatial resolution $50 \mu \mathrm{m}$.

Table I. Experimental conditions during gradation of $\mathrm{Bi}_{x} \mathrm{Sb}_{1-x}$ samples

\begin{tabular}{|c|c|c|c|c|}
\hline Sample & Composition & Sedimentation Time (h) & Acceleration $\left(10^{6} \mathrm{G}\right)$ & Temperature (K) \\
\hline A & $\mathrm{Bi}_{60} \mathrm{Sb}_{40}$ & 60 & 0.55 & 623 \\
\hline B & $\mathrm{Bi}_{70} \mathrm{Sb}_{30}$ & 60 & 0.55 & 623 \\
\hline C & $\mathrm{Bi}_{80} \mathrm{Sb}_{20}$ & 60 & 0.55 & 538 \\
\hline D & $\mathrm{Bi}_{90} \mathrm{Sb}_{10}$ & 60 & 0.55 & 538 \\
\hline
\end{tabular}

chamber (with temperature controlled with $1 \mathrm{~K}$ accuracy) under reduced pressure $\left(10^{2} \mathrm{~Pa}\right)$ of air.

The large centrifugal force and high temperature caused deformation of the FGTM samples. After sedimentation, the samples had cylindrical shape with diameter of $5 \mathrm{~mm}$ and thickness of $1 \mathrm{~mm}$ to $2 \mathrm{~mm}$. Samples were cut in half to observe the changes in the chemical composition and physical properties.

\section{RESULTS AND DISCUSSION}

The results of the measurements of thermoelectric properties of reference samples are given in Figs. 4,5 , and 6 . All samples had $n$-type conductivity, exhibiting the highest Seebeck coefficient between $-90 \mu \mathrm{V} / \mathrm{K}$ and $-55 \mu \mathrm{V} / \mathrm{K}$ at room temperature.

The absolute value of $\alpha$ decreased with increasing temperature. The samples revealed metallic character in the electrical conductivity, with highest values between $5.3 \times 10^{5} \mathrm{~S} / \mathrm{m}$ and $6.5 \times 10^{5} \mathrm{~S} / \mathrm{m}$ at room temperature (RT), decreasing with temperature increase. The power factor $\alpha^{2} \sigma$ of each sample reached a maximum at about $323 \mathrm{~K}\left(4.0 \times 10^{-3}\right.$ for sample D). These results for the thermoelectric properties are in good agreement with those reported in literature for $300 \mathrm{~K}$ (Table II).

The changes in microstructure (Fig. 7), chemical composition (Fig. 8), and Seebeck coefficient distribution (Figs. 9, 10, and 11) after sedimentation were analyzed. It was found that, in the case of the $\mathrm{Bi}_{60} \mathrm{Sb}_{40}, \mathrm{Bi}_{70} \mathrm{Sb}_{30}$, and $\mathrm{Bi}_{80} \mathrm{Sb}_{20}$ samples, the

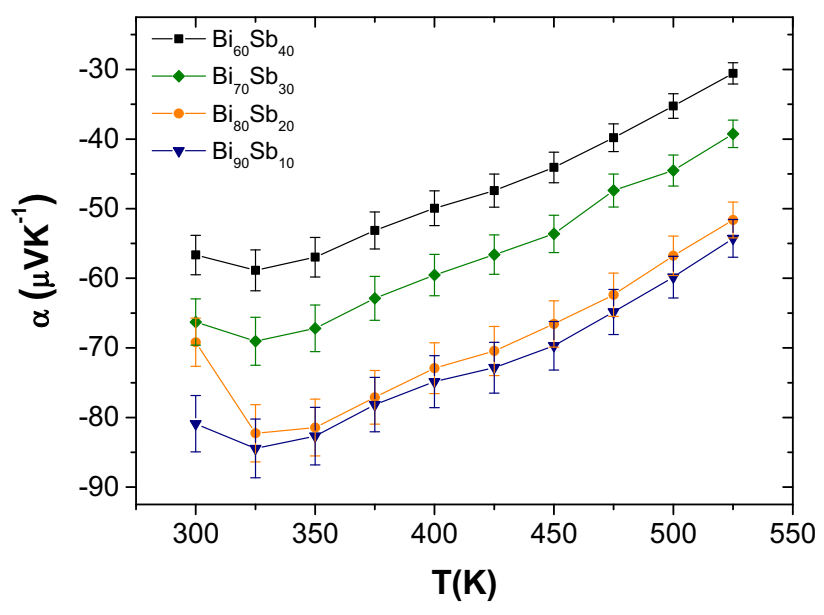

Fig. 4. Seebeck coefficient of reference samples as a function of temperature. Data were collected during heating and cooling mode; average values are shown.

concentration of $\mathrm{Sb}$ decreased sharply at depth of approximately $225 \mu \mathrm{m}, 375 \mu \mathrm{m}$, and $750 \mu \mathrm{m}$ (from the right hand side) (Fig. 7). In these areas, a clear border was visible between the Bi-rich and Sb-rich parts of the sample. For the $\mathrm{Bi}_{90} \mathrm{Sb}_{10}$ sample, even though gradation in the microstructure could be observed, the amount of $\mathrm{Bi}$ and $\mathrm{Sb}$ changed slightly.

The sedimentation depth depends on the diffusion coefficient of the component in the material. The diffusion coefficient of the element is related 


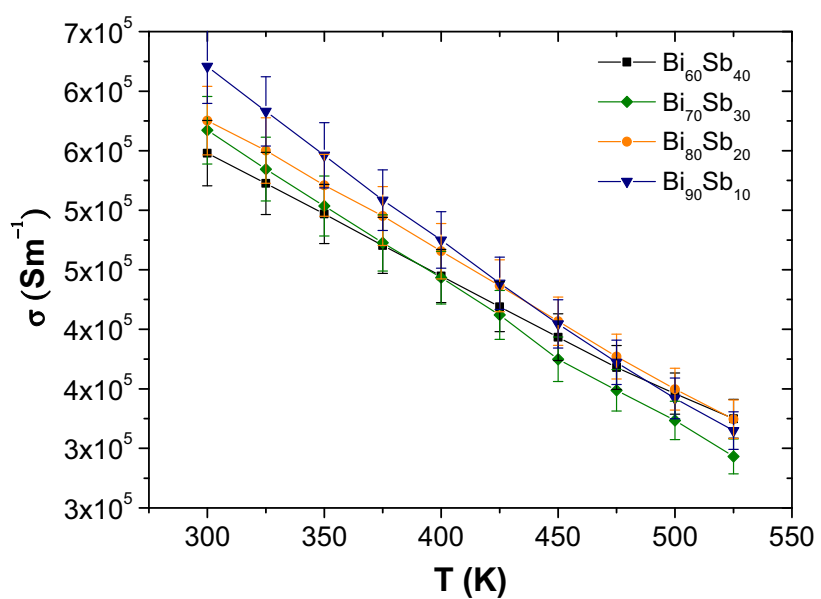

Fig. 5. Electrical conductivity of reference samples as a function of temperature. Data were collected during heating and cooling mode; average values are shown.



Fig. 6. Power factor of reference samples before gradation as a function of temperature. Data were collected during heating and cooling mode; average values are shown. to the melting temperature and increases near the melting temperature of the alloy. The melting points of pure $\mathrm{Bi}$ and $\mathrm{Sb}$ are $544.7 \mathrm{~K}$ and $903.8 \mathrm{~K}$, respectively, so the melting point of $\mathrm{Bi}-\mathrm{Sb}$ alloy increases with the Sb content. As a result, the diffusion coefficient and sedimentation depth decrease with increase in the Sb content.

In the $\mathrm{Bi}_{60} \mathrm{Sb}_{40}$ sample, microstructural defects (pores) accumulated at the border between the $\mathrm{Bi}$ rich and Sb-rich regions are clearly visible. The presence of pores can be a result of the Kirkendall effect, i.e., accumulation of vacancies when the difference in diffusion rates of two elements (in this case $\mathrm{Bi}$ and $\mathrm{Sb}$ ) is too large. Pores influence the mechanical, thermal, and electrical properties, and thus control over their formation is desired. Usually, lowering the annealing temperature reduces or even eliminates porosity, as was indeed confirmed by our observations: the amount of pores in samples (C and D) prepared at lower temperature of $538 \mathrm{~K}$ was significantly lower than in samples graded at $623 \mathrm{~K}$.

Figure 9a shows a map of the distribution of the Seebeck coefficient for the $\mathrm{Bi}_{90} \mathrm{Sb}_{10}$ sample. The sample is uniform; the corresponding histogram (Fig. 9c) presents a unimodal distribution of $\alpha$ with relatively small standard deviation $\sigma$. The accuracy of the measurement is shown in Fig. 9b by a map of the Seebeck coefficient error. Because the determined apparatus error $(\sim 1.5 \mu \mathrm{V} / \mathrm{K})$ is significantly smaller than the standard deviation $\sigma$ (Fig. 9c), we conclude that the nonuniformity of the material is described quite well.

The histograms of the Seebeck coefficient distributions in Figs. 9c, 10b, and 11 can be described by normal distributions,

$$
f(x \mid \mu, \sigma)=\frac{1}{\sigma \sqrt{2 \pi}} \mathrm{e}^{-\frac{(x-\mu)^{2}}{2 \sigma^{2}}},
$$

where $\mu$ is the mean (expectation parameter) of the distribution and $\sigma$ is its standard deviation (dispersion parameter).

Table II. Electrical properties of Bi-Sb alloys in other works and in this study at $300 \mathrm{~K}$

\begin{tabular}{|c|c|c|c|}
\hline \multirow[b]{2}{*}{ Composition } & \multicolumn{2}{|c|}{ Values } & \multirow[b]{2}{*}{ Reference } \\
\hline & Seebeck Coefficient $(\mu \mathrm{V} / \mathrm{K})$ & Electrical Conductivity (S/m) & \\
\hline $\mathrm{Bi}_{83} \mathrm{Sb}_{17}-\mathrm{Bi}_{90} \mathrm{Sb}_{10}$ & From -80 to -90 & No data & 38 \\
\hline $\mathrm{Bi}_{92.5} \mathrm{Sb}_{7.5}$ & No data & $1 \times 10^{5}$ & 39 \\
\hline $\mathrm{Bi}_{91} \mathrm{Sb}_{9}-\mathrm{Bi}_{98} \mathrm{Sb}_{2}$ & From -65 to -90 & $2.5-5.0 \times 10^{5}$ & 40 \\
\hline $\mathrm{Bi}_{91.5} \mathrm{Sb}_{9.5}-\mathrm{Bi}_{96} \mathrm{Sb}_{4}$ & From -80 to -100 & Approx. $1 \times 10^{6}$ & 41 \\
\hline \multicolumn{4}{|l|}{ This study } \\
\hline $\mathrm{Bi}_{60} \mathrm{Sb}_{40}$ & -56 & $5.5 \times 10^{5}$ & - \\
\hline $\mathrm{Bi}_{70} \mathrm{Sb}_{30}$ & -68 & $5.7 \times 10^{5}$ & \\
\hline $\mathrm{Bi}_{80} \mathrm{Sb}_{20}$ & -78 & $5.8 \times 10^{5}$ & \\
\hline $\mathrm{Bi}_{90} \mathrm{Sb}_{10}$ & -81 & $6.2 \times 10^{5}$ & \\
\hline
\end{tabular}





Fig. 7. Microstructure and chemical composition of samples before $\left[(a) \mathrm{Bi}_{60} \mathrm{Sb}_{40}\right.$, (b) $\mathrm{Bi}_{90} \mathrm{Sb}_{10}$ (NOVA NANO SEM 200)] and after gradation experiment at $623 \mathrm{~K}\left[(\mathrm{c}) \mathrm{Bi}_{60} \mathrm{Sb}_{40}\right.$, (d) $\left.\mathrm{Bi}_{70} \mathrm{Sb}_{30}\right]$ and $538 \mathrm{~K}\left[(\mathrm{e}) \mathrm{Bi}_{80} \mathrm{Sb}_{20}\right.$, (f) $\left.\mathrm{Bi}_{90} \mathrm{Sb}_{10}\right]$ (JEOL JSM-6460LV).

Figure 10 shows the results of analysis of the anisotropy of the Seebeck coefficient for a reference sample. The mean Seebeck coefficient values $\mu_{1}$ and $\mu_{3}$ for surfaces 1 and 3, parallel to the direction of crystal growth, are practically the same within the measurement error $(1.5 \mu \mathrm{V} / \mathrm{K})$. The mean value $\mu_{2}$ of the absolute Seebeck coefficient for surface 2, which is perpendicular to the direction of crystal growth, is slightly higher $(71 \mu \mathrm{V} / \mathrm{K})$ than for the other surfaces. The standard deviations $\left(\sigma_{1}, \sigma_{2}, \sigma_{3}\right)$ describing the nonuniformity of the Seebeck coefficient distribution lie between $3 \mu \mathrm{V} / \mathrm{K}$ and $5 \mu \mathrm{V} / \mathrm{K}$. These values are very low and close to each other. Therefore, we conclude that the sample is almost uniform and exhibits slight anisotropy of thermoelectric properties. Therefore, the results of the measurements of the thermoelectric properties for samples before and after gradation are comparable if the gradation is applied in the growth direction.

Comparison of the results of EDX analysis and Seebeck coefficient distribution in graded samples shows that the changes in chemical composition are strongly correlated with the thermoelectric properties. The distribution of the Seebeck coefficient after sedimentation can have multimodal character (Fig. 11); For example, in the case of the $\mathrm{Bi}_{70} \mathrm{Sb}_{30}$ sample, sedimentation leads to the formation of a trimodal distribution with modes $\mu_{1}=-63 \mu \mathrm{V} / \mathrm{K}$, $\mu_{2}=-42 \mu \mathrm{V} / \mathrm{K}$, and $\mu_{3}=-21 \mu \mathrm{V} / \mathrm{K}$, corresponding to the $\mathrm{Bi}-\mathrm{Sb}$ mixed (70\% to $90 \% \mathrm{Bi}$ ), Bi-rich $(90 \%$ to $100 \% \mathrm{Bi})$, and $\mathrm{Sb}-$ rich $(45 \%$ to $70 \% \mathrm{Bi})$ regions, respectively (Fig. 11b).

Electronic structure calculations show that $\mathrm{Bi}-\mathrm{Sb}$ alloys can exhibit semimetallic or semiconductive 


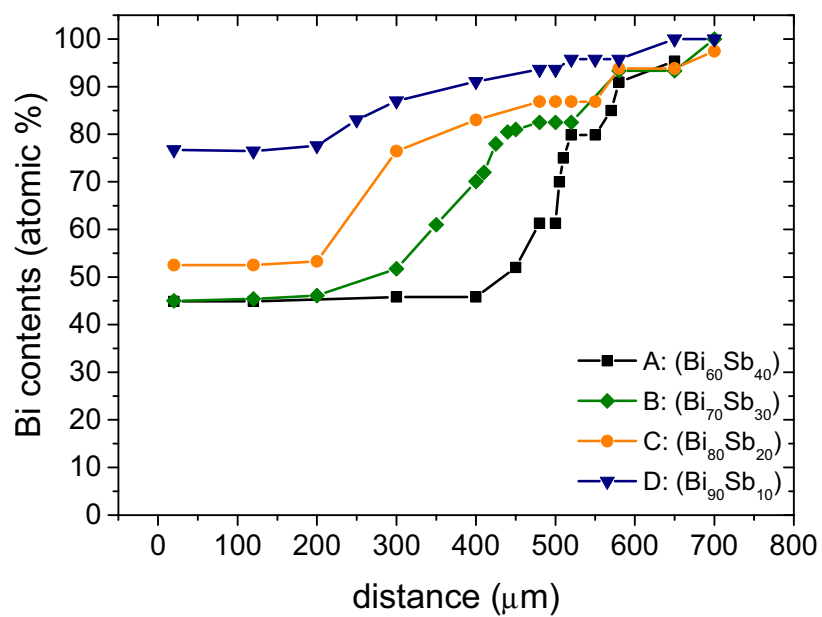

Fig. 8. Change of chemical composition with distance from left edge of sample. properties, depending on the chemical composition. $^{41}$ It was found that Bi-Sb alloy is a semiconductor for Bi content between 78 at.\% and 93 at.\%. For this region, the absolute values of the Seebeck coefficient should be the highest. The theoretical bandgap in this range changes between $0 \mathrm{meV}$ and $150 \mathrm{meV}$, but experimental values are below $25 \mathrm{meV}$ for temperatures below $100 \mathrm{~K}$. Above this temperature, the dependence of the electrical conductivity corresponds to semimetallic behavior. The aforementioned theoretical predictions are consistent with our experimental results (Fig. 5). In the semiconducting region, the absolute Seebeck coefficient values $(\alpha \max \approx-100 \mu \mathrm{V} / \mathrm{K}$ to $-80 \mu \mathrm{V} / \mathrm{K})$ are the highest. For the Bi-rich region between 96 at.\% and 100 at.\%, the Seebeck coefficient is about $-70 \mu \mathrm{V} / \mathrm{K}$ and close to the value reported for pure Bi. For Sb-rich regions, the Seebeck coefficient increases with the $\mathrm{Sb}$ content and can reach values (a)
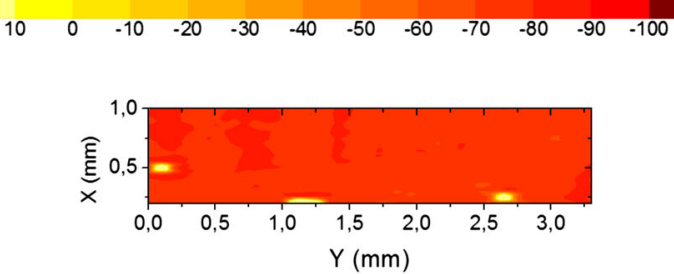

(b)

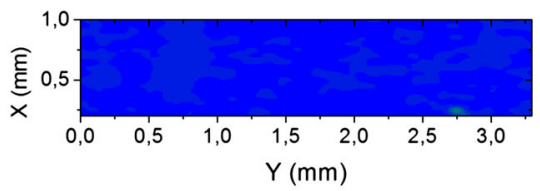

$\begin{array}{lllllllllll}0 & 0.5 & 1.0 & 1,5 & 2.0 & 2.5 & 3,0 & 3.5 & 4,0 & 4,5 & 5,0\end{array}$ (c)

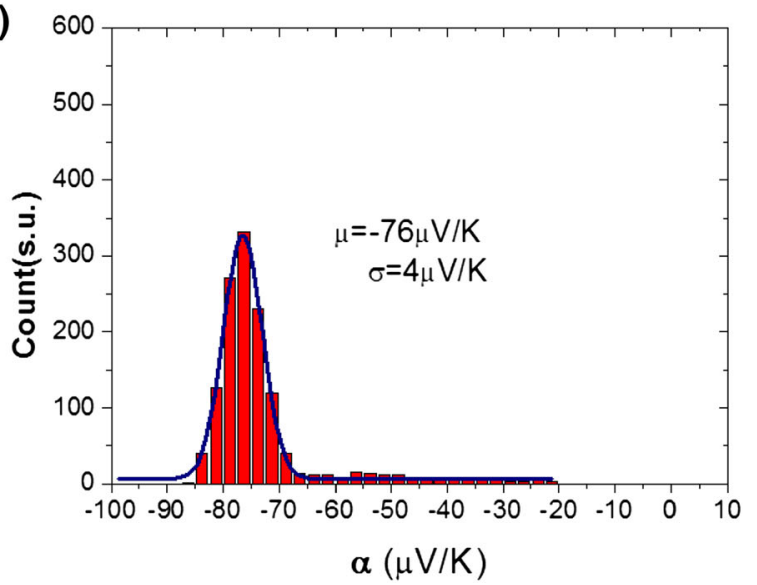

Fig. 9. (a) Seebeck coefficient map in a uniform sample $\left(\mathrm{Bi}_{90} \mathrm{Sb}_{10}\right)$. (b) Map of standard deviations for single measurement. (c) Distribution of Seebeck coefficient with mean value $(\mu)$ and st. dev. $(\sigma)$; spatial resolution $50 \mu \mathrm{m}$.

(a)

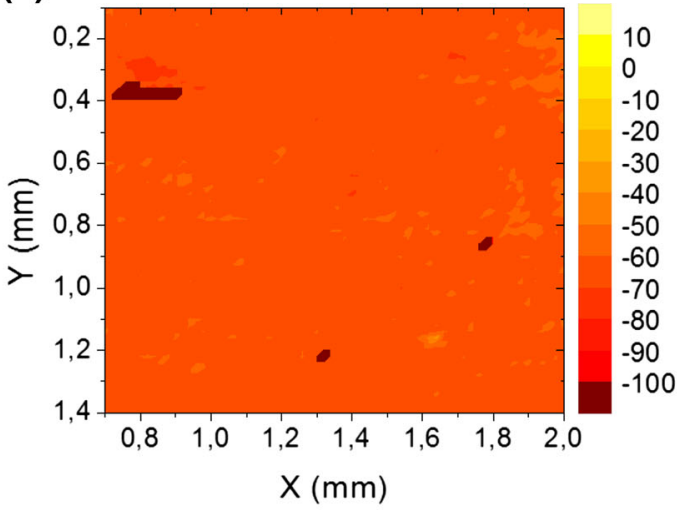

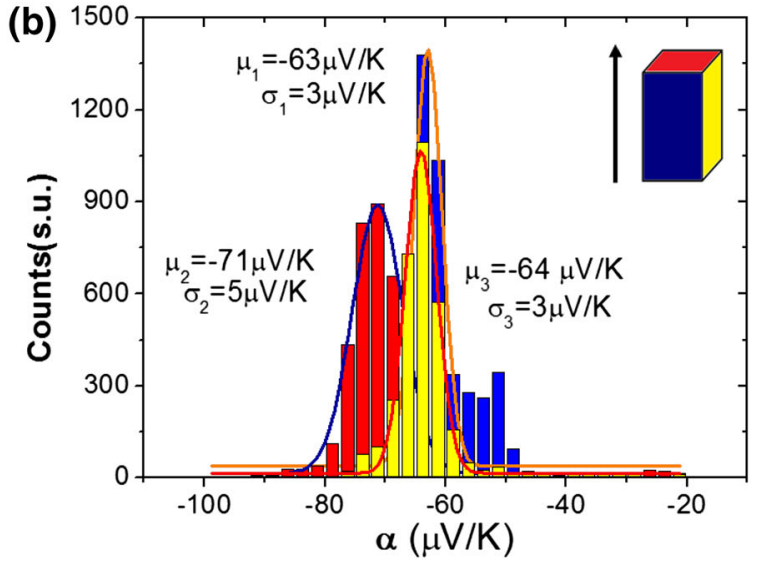

Fig. 10. (a) Seebeck coefficient map in reference sample $\left(\mathrm{Bi}_{80} \mathrm{Sb}_{20}\right)$ before gradation procedure-surface 1; spatial resolution $20 \mu \mathrm{m}$. (b) Distribution of coefficient in this sample depending on the measured surface: surface 1 and 3 are parallel to direction of crystallization, while surface 2 is perpendicular. 

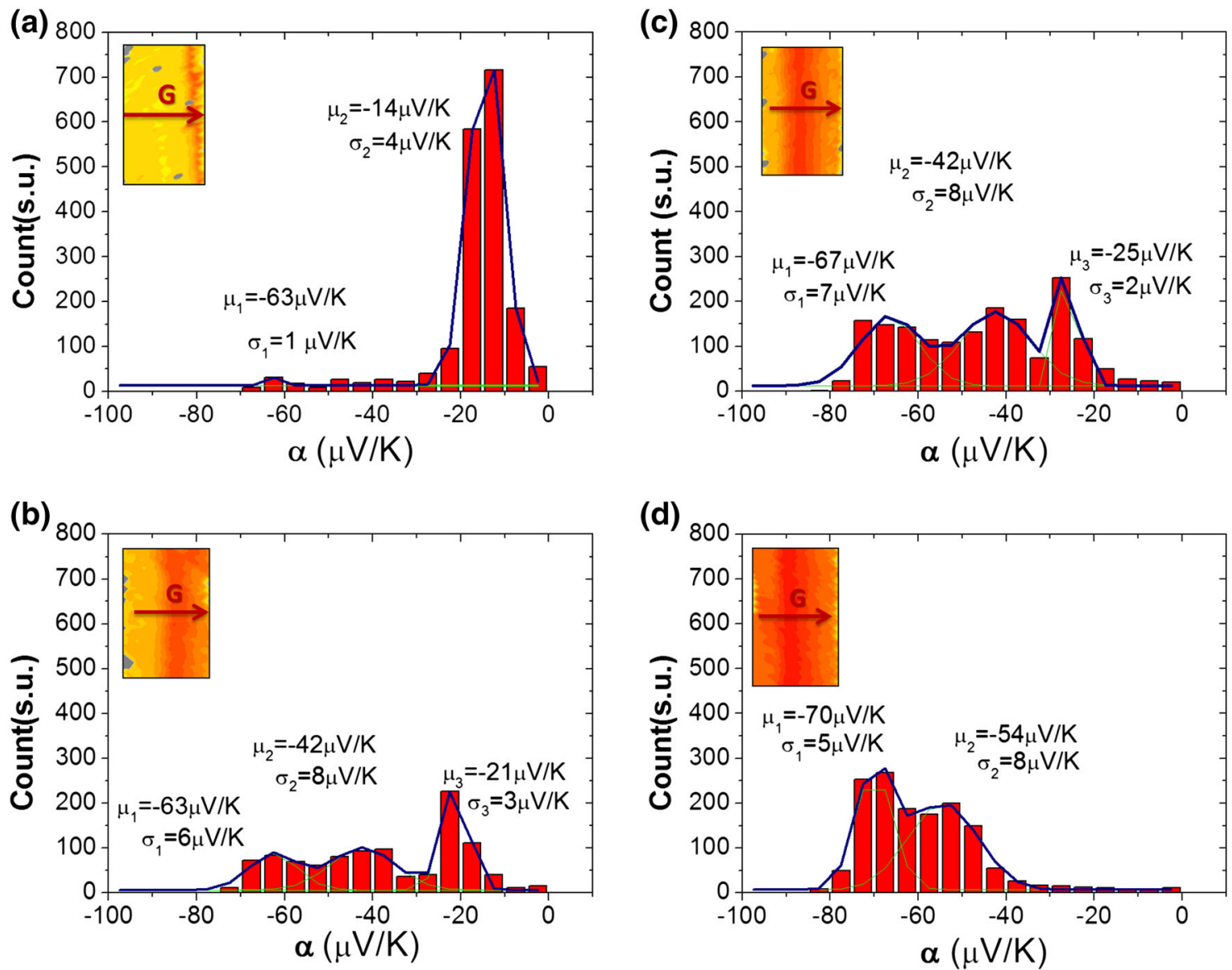

Fig. 11. Seebeck coefficient distributions and maps after gradation for sample (a) $\mathrm{Bi}_{60} \mathrm{Sb}_{40}$, (b) $\mathrm{Bi}_{70} \mathrm{Sb}_{30}$, (c) $\mathrm{Bi}_{80} \mathrm{Sb}_{20}$, and (d) $\mathrm{Bi}_{90} \mathrm{Sb}_{10}$, with mean value $(\mu)$ and st. dev. $(\sigma)$; spatial resolution $50 \mu \mathrm{m}$.

of $+35 \mu \mathrm{V} / \mathrm{K}$ for pure antimony. These values correspond very well to our results presented in Figs. 4, 9 and 11 and explain the trimodal Seebeck coefficient distribution.

\section{CONCLUSIONS}

In a series of sedimentation experiments, a set of graded $\mathrm{Bi}_{x} \mathrm{Sb}_{1-x}$ alloys with large changes in chemical composition ( $x=0.45$ to 1$)$ and variable Seebeck coefficient distribution were prepared. The experiments allowed the determination of the main processing parameters influencing the chemical and microstructural properties of the resulting materials. It was found that the changes in the chemical composition of the graded materials were strongly correlated with the alterations of the Seebeck coefficient. These first experimental data are essential for further optimization of the processing parameters for controlled preparation of FGTM materials with required profiles of thermoelectric properties.

\section{ACKNOWLEDGEMENTS}

This research work was supported by the National Science Center through funding granted according to Project No. DEC-2012/05/N/ST8/03390 in Poland, and the G-COE program for the part conducted at Kumamoto University, Japan.

\section{CONFLICT OF INTEREST}

The authors declare that they have no conflict of interest.

\section{OPEN ACCESS}

This article is distributed under the terms of the Creative Commons Attribution 4.0 International License (http://creativecommons.org/licenses/by/4.0/), which permits unrestricted use, distribution, and reproduction in any medium, provided you give appropriate credit to the original author(s) and the source, provide a link to the Creative Commons license, and indicate if changes were made.

\section{REFERENCES}

1. K.T. Wojciechowski., R. Zybala, J. Leszczynski, P. Nieroda, M. Schmidt, R. Gajerski, and S. Aleksandrowa, in AIP Conference Proceedings 9th European Conference on Thermoelectrics (ECT2011), Thessaloniki, September 2011, p. 467. 
2. T. Caillat, J.-P. Fleurial, J. Snyder, A. Zoltan, B. Zoltan, and A. Borshchevsky, in IEEE Eighteenth International Conference on Thermoelectrics (ICT'99), Baltimore, September 1999, p. 473.

3. M.S. El-Genk and H.H. Saber, Energy Convers. Manag. 44, 1069 (2003).

4. P.H. Ngan, D.V. Christensen, G.J. Snyder, L.T. Hung, S. Linderoth, N.V. Nong, and N. Pryds, Phys. Status Solidi A 211, 9 (2014).

5. L.N. Vikhor and L.I. Anatychuk, Energy Convers. Manag. 50, 2366 (2009).

6. G.J. Snyder, in Thermoelectric Handbook, Macro to Nano, ed. by D.M. Rowe (Boca Raton: CRC Press, 2006), pp. 9-1.

7. L.I. Anatychuk, L.N. Vikhor, L.T. Strutynska, and I.S. Termena, J. Electron. Mater. 40, 957 (2011).

8. T. Caillat, J.-P. Fleurial, G.J. Snyder, and A. Borshchevsky, in IEEE 20th International Conference on Thermoelectrics (ICT2001), Beijing, June 2001, p. 282.

9. G. Rogl, A. Grytsiv, P. Rogl, E. Bauer, M.B. Kerber, M. Zehetbauer, and S. Puchegger, Intermetallics 18, 2435 (2010).

10. K. Biswas, J. He, I.D. Blum, C.I. Wu, T.P. Hogan, D.N Seidman, V.P. Dravid, and M.G. Kanatzidis, Nature 489, 413 (2012).

11. G.J. Snyder, Appl. Phys. Lett. 84, 2436 (2004).

12. A. Odia, L.F.Llin; D.J. Paul, S. Cecchi, and G. Isella, in IEEE 11th Conference on Ph.D. Research in Microelectronics and Electronics (PRIME), Glasgow, July 2015, p. 254

13. X.W. Wang, H. Lee, Y.C. Lan, G.H. Zhu, G. Joshi, D.Z Wang, J. Yang, A.J. Muto, M.Y. Tang, J. Klatsky, S. Song, M.S. Dresselhaus, G. Chen, and Z.F. Ren, Appl. Phys. Lett. 93, 193121 (2008).

14. T. Caillat and J.-P. Fleurial, in IEEE 31st Intersociety Energy Conversion Engineering Conference (IECEC 96), Washington, August 1996, p. 905.

15. M. Chitroub, F. Besse, and H. Scherrer, J. Alloys Compd. 460, 90 (2008)

16. J. LaGrandeur, D. Crane, S. Hung, B. Mazar, and A. Eder, in IEEE Twenty-Fifth International Conference On Thermoelectrics (ICT'06), Vienna, August 2006, p. 343.

17. E. Skrabek and D. Trimmer, CRC Handbook of Thermoelectrics, ed. D.M. Rowe (Boca Raton: CRC Press, 1995), p. 267

18. A.F. Ioffe, SU author's Certificate No. 126158, Claimed August 19, 1949 (1949).

19. K. Wojciechowski, DIMAT2014 (2014).

20. W. Seifert and V. Pluschke, Phys. Status Solidi B 251, 1416 (2014)

21. W. Seifert, G.J. Snyder, E.S. Toberer, C. Goupil, K. Zabrocki, and E. Müller, Phys. Status Solidi A 210, 1407 (2013).
22. Z.H. Jin, T.T. Wallace, R.J. Lad, and J. Su, J. Electron. Mater. 43, 308 (2014).

23. G.D. Mahan, J. Appl. Phys. 70, 4551 (1991).

24. A.L. Jain, Phys. Rev. 114, 1518 (1959).

25. Y. Shinohara, Y. Imai, Y. Isoda, and H.T. Kaibe, Functionally Graded Materials 2000, ed. K. Trumble, K. Bowman, I. Reimanis, and S. Sampath (Ohio: The American Ceramic Society, 2001), p. 39.

26. L.D. Ivanova, L.I. Petrova, Yu. V. Granatkina, T.E. Svechnikova, M.A. Korzhuev, and V.S. Zemskov, Inorg. Mater. 43, 1291(2007)

27. V.L. Kuznetsov, L.A. Kuznetsova, A.E. Kaliazin, and D.M. Rowe, J. Mater. Sci. 37, 2893 (2002).

28. T. Mashimo, X. Huang, T. Osakabe, M. Ono, M. Nishihara, H. Ihara, M. Sueyoshi, K. Shibasaki, S. Shibasaki, and N. Mori, Rev. Sci. Instrum. 74, 160 (2003).

29. T. Mashimo, M. Ono, T. Kinoshita, X. Huang, T. Osakabe, and H. Yasuoka, Phil. Mag. Lett. 83, 687 (2003).

30. X. Huang, M. Ono, H. Ueno, Y. Iguchi, T. Tomita, S. Okayasu, and T. Mashimo, J. Appl. Phys. 101, 113502 (2007).

31. T. Mashimo, T. Ikeda, and I. Minato, J. Appl. Phys. 90, 741 (2001).

32. X. Huang, T. Mashimo, M. Ono, T. Tomita, T. Sawai, T. Osakabe, and N. Mori, J. Appl. Phys. 96, 1336 (2004).

33. G.E. Smith and R. Wolfe, J. Appl. Phys. 33, 841 (1962).

34. N.Ya. Minina and L.A. Kirakozova, Sov. Phys. JETP 74, 886 (1992); Russian Original: ZhETF, 101, 1663, (1992).

35. H.J. Goldsmid and J.W. Sharp, in IEEE Fifteenth International Conference on Thermoelectrics (ICT'96), Pasadena, March 1996, p. 14

36. R. Martin-Lopez, A. Dauscher, H. Scherrer, J. Hejtmanek, H. Kenzari, and B. Lenoir, Appl. Phys. A 68, 597 (1999).

37. B. Lenoir, H. Scherrer, and T. Caillat, Semiconductors and Semimetals 69, ed. T. Tritt (San Diego: Academic Press, 2001), p. 101

38. H. Kitagawa, H. Noguchi, T. Kiyabu, M. Itoh, and Y. Noda, J. Phys. Chem. Solids 65, 1223 (2004).

39. M. Miyajima, K. Takagi, H. Okamura, G.G. Lee, Y. Noda, and R. Watanabe, in IEEE Fifteenth International Conference on Thermoelectrics (ICT'96), Pasadena, March 1996, p. 18.

40. E.I. Rogacheva, A.A. Drozdova, and M.S. Dresselhaus, in IEEE Twenty-Fifth International Conference On Thermoelectrics (ICT'06), Vienna, August 2006, p. 107.

41. B. Lenoir, A. Dauscher, X. Devaux, R. Martin-Lopez, Y.I. Ravich, H. Scherrer, and S. Scherrer, in IEEE Fifteenth International Conference on Thermoelectrics (ICT'96), Pasadena, March 1996, p. 1. 